J. clin. Path. (1949), 2, 61.

\title{
INTRA-MEDULLARY CYST OF THE SPINAL CORD DUE TO THE CESTODE MULTICEPS MULTICEPS IN THE COENURUS STAGE
}

\author{
REPORT OF A CASE
}

BY

\author{
J. W. LANDELLS
}

From the Bernhard Baron Institute of Pathology, London Hospital

(RECEIVED FOR PUBLICATION, OCTOBER 1, 1948)

The cestode Multiceps multiceps is well known as a cause of intracerebral cysts in sheep, but there are only three reports of similar human infestation certainly due to this particular parasite (Brumpt, 1936 ; Clapham, 1941 ; Cluver, quoted by Craig and Faust, 1943). The subcutaneous tissues in man have been more frequently involved; there are some eight reports from various continents. The case now to be detailed is the first in which the spinal cord has been affected. A parallel case of hydatid cyst in the spinal canal has been published by Rogers and Tudhope (1938); the measurements of the hooklets in their case and the present case establish the different species involved.

\section{Case Report}

A girl aged 14 was admitted to the Brentwood Annexe of the London Hospital under Mr. Northfield on Feb. 15, 1947. She was suffering from spastic paraplegia of acute onset at the level of the sixth thoracic segment; her earliest symptom, "pins and needles in her legs," appeared and increased in intensity only four weeks before motor and sensory paralysis became complete. Double incontinence followed three weeks later, but she never complained of any pain.

Laminectomy and exploration of the cord were undertaken on Feb. 19, 1947, on a clinical diagnosis of intra-medullary tumour, the spines and laminae of the fourth to the ninth thoracic vertebrae being removed. The dura was tightly stretched over a swelling of the cord, the surface of which was irregular and had a patchy bluish discoloration. A midline incision was made into the posterior surface of the cord at about the fifth and sixth thoracic segments, and a thin-walled cyst, which presented itself spontaneously through the opening, was easily and apparently completely delivered by gentle traction; it had no visible attachment to the cord. The para:ysis did not improve, and a second operation a month later, exposing the whole length of the cord from the fourth to the ninth thoracic segments, showed no further cysts and no visible cause for the continuing paralysis. During ten months since this second operation there has been very slight sensory recovery but no motor recovery, and increasingly severe and painful flexor spasms have required relief by cordotomy.

Special investigations.--Four examinations of the blood showed no eosinophilia, 450 eosinophils or fewer being counted in 6,100 to 9,200 white cells.

The Casoni test was negative, but was not tried until some weeks after the removal of the cyst.

In already reported cases there is no record of blood examinations. Casoni tests in two patients with subcutaneous coenuri-described as Multiceps serialiswere also negative.

Further inquiry about the patient revealed that she had never been abroad, but had been evacuated during the war to Glamorgan, where the worm is common enough, and here she had been in close contact with the sheepdogs at a farm. She returned to Kent a year before the onset of her illness; there had been possible contact with a young puppy-an unlikely carrier of the definitive stage-but no close or frequent contact with other animals.

Pathological examination.-The cyst (Fig. 1) was received already fixed in formol-saline, and consisted of a chain of vesicles attached to each other in a twisted and tangled group; individual vesicles were up to $0.6 \mathrm{~cm}$. in diameter and had filmy transparent grey walls with white nodules $(0.1 \mathrm{~cm}$. in diameter), varying in number from two or three up to thirty, on the inner surface. These nodules were usually in small groups (up to eighteen) but also occurred singly.

When a nodule was compressed under a cover-slip and examined under low magnification it showed the four suckers and double row of hooklets characteristic of a Taeniid cestode (Fig. 2): the multiple scolices in each vesicle identified the type of cyst as a coenurus, Professor Buckley, of the London School of Hygiene and Tropical Medicine, very kindly completed the identification by measurement of the hooklets as Multiceps multiceps, the sheep gid-worm. Unfortunately, as all the material was fixed in formalin, this could not be confirmed by identification of the 
definitive stage by passage through a puppy. Further helminthological details of this case have since been published by Crusz (1948).

Histology. - A group of scolices and part of the cyst wall were embedded in paraffin and sections were stained with haematoxylin and eosin, iron haemotoxylin and van Gieson, and Mallory's phosphotungstic acid haematoxylin.

The cyst separated cleanly from the tissues of the spinal cord, no part of which was present in sections. The outer wall consisted of homogeneous eosinophil material $50 \mu$ thick, thrown up into very numerous rounded wrinkles 20 to $30 \mu$ in diameter; the fibres composing the wall formed a coarse reticulum. On the inner surface was a spongy parenchyma with numerous small rounded nuclei, often in groups; the confluence of vacuoles of this parenchyma formed the cyst cavity. The scolices were developed in outgrowths of the parenchyma by invagination from the cyst; this invagination appeared in section as irregular cleft lined by the cuticle of the scolex (Fig. 3). This was a smooth, uniform, tibreless membrane (10 $\mu$ thick) much folded, which stained a deeper and more purple tint in haematoxylin and eosin than the outer cyst wall. The suckers and hooklets are easily made out in the apex of the invaginations (Fig. 4).

For further study of the reactions of the host to the cyst I am indebted to Professor L. P. Garrod for the loan of a slide, stained with haematoxylin and eosin, of the cyst in Clapham's case, and to Professor Buckley for a sheep brain containing a coenurus.

The human material shows separation of the cyst wall from the brain by a space of 250 to $500 \mu$. This is clearly a natural line of cleavage of which the surgeons in my case took advantage. From the border of this gap, four zones can be made out in the brain before normal nervous tissue is reached, at the depth of some $3 \mathrm{~mm}$. from the cyst wall.

1. The first zone $(100 \mu$ deep $)$ is extensively necrotic and is composed of angular, sometimes multinucleated cells, orientated at right angles to the cyst and separated by numerous clefts and spaces. Preservation is too poor to determine the character of the cells but some undoubtedly are macrophages.

2. The second, less well defined zone (100 to $300 \mu$ ) consists of delicate fibrous tissue, the fibres lying parallel to the surface.

3. The main zone of cellular infiltration succeeds this with an indefinite boundary and is up to $700 \mu$ thick, though averaging only $200 \mu$. The infiltration, denser round small blood vessels, is mainly of small lymphocytes with a few plasma cells. Hyaline, probably collagenous, areas with spindle cells are also present, and a larger arter. is undergoing purulent inflammation and necrosi⿸户

4. In the nervous tissue proper there is ag increase of large plump astrocytes which ace arranged in such a way as to suggest severe compression; this zone is oedematous in placs and up to $400 \mu$ wide. The adjacent cortex showas chromatolysis and dropsical degeneration of a large number of pyramidal cells.

Collectively these observations indicate a chronie granulomatous inflammation forming a zone least $3 \mathrm{~mm}$. deep around the parasite. In the spinal cord a corresponding zone would be at greater functional importance than in the brain, and the clinical course of the case and the nors recovery after the removal of the cyst are th $\$$ easily explained.

In material from the sheep there is again a vert obvious line of cleavage between the cyst wall and the reaction zone of giant cells, fibrin depositio and necrosis in the adjacent tissue. This zone a great deal wider than in the human, and the giant cells are more numerous and much larged There is rather less small round-cell infiltration. and no necrosis in the outer adjacent zone. Traces of collagen are present in the edges of the moro intense reaction.

Although, therefore, there is a very intensक्ष reaction to the presence of the cyst, this latter dos not become incorporated in the host tissues, and can be expected to "shell" out on surgical manipl? lation : and, unless compression has already resulted in severe damage to important nervous tissues: operative treatment should have a very good chance of success.

\section{Literature}

Crusz (1948) has reviewed from the helminth@ logical point of view the cases of coenuros? reported in man, including the present case, ang both he and Clapham (1942) consider that the three types given specific rank by previous autho: (for example Faust) are not true species but rather physiological strains or immature stages of the single species $M$. multiceps. In Brumpt's repo: a Parisian locksmith, aged 40, presented with fits and aphasia and was found at autopsy eig通 months later to have two cysts, one in the posterio horn of the left lateral ventricle and one in the le angular gyrus; the latter was degenerate and con tained only hooklets, but 75 scolices were found in the ventricular cyst.

No details of the case reported by Cluver in the lateral ventricle of an African are available : the original reference (not given by Faust) cannot bo traced. 
For my knowledge of the clinical details of Clapham's case I am indebted to Dr. D. H. Fulton, pathologist to Peterborough Hospital. A man of 40 was found in coma in his bedroom and died 20 hours later, his relatives apparently mistaking his illness for acoholism. He had served in the Navy from the age of 18 to 32 and had been well apart from an attack of meningococcal meningitis at the age of 18. At the age of 36 he had the first of increasingly frequent and severe sudden headaches, which lasted up to 24 hours. He had no fits or paralyses. At autopsy the right cerebral hemisphere was larger than the left; on section a thin-walled cyst $5 \mathrm{~cm}$. in diameter by $8 \mathrm{~cm}$. from front to back was found above and lateral to the right lateral ventricle; its inner wall was studded with white, raised areas, and it contained clear fluid. The left hemisphere and the cerebellum were normal. A massive haemorrhage had occurred in the pons and medulla and was the cause of death. The thoracic and abdominal organs were normal. He had died with arms and legs extended and with hands tightly clenched. His headaches with their paroxysmal onset resemble those occurring with colloid cyst of the third ventricle or the headache of acute internal hydrocephalus, and a terminal pontine or mid-brain haemorrhage is a not uncommon sequel to increased supratentorial pressure. The infection was probably acquired in this country rather than during his Naval service. This is suggested both by the lapse of four years between leaving the service and the onset of the headaches, which may be taken as marking the onset of the cerebral lesion, and by the life history of the parasite. This develops to full maturity in the sheep in about eight months (Neveu-Lemaire, 1936); it is then about 3 to $5 \mathrm{~cm}$. in diameter and causes softening of the overlying skull. It occurs all over the world where sheep-raising is carried on, the definitive stage being passed in the intestine of the dog or wolf and the intermediate cyst (Coenurus) stage in the central nervous system of herbivores. In this country it is fairly well known in the Welsh sheep farms; but the Chief Inspector of Abattoirs in Cardiff has only seen two cases in twenty years, since the sheep commonly die on the farms. In some cases the shepherds remove the cysts with their penknives, locating them by the softening of the skull. The name "gid-worm" is derived from the staggering of the sheep when affected by the parasite.

I am indebted to Mr. D. W. C. Northfield for the clinical notes, and to Professor J. J. C. Buckley, Professor L. P. Garrod, Dr. D. H. Fulton, and Dr. Phyllis Clapham for assistance with the parasitology and the records of previous cases. I also wish to thank Professor D. S. Russell for help in preparing the paper and Mr. A. J. King for the photographs.

\section{REFERENCES}

Brumpt, E. (1936). "Précis de Parasitologie." 5th Edit., Paris. Vol. 1, p. 738. (Originally reported in 1911.)

Clapham, P. A. (1941). J. Helminthology, 19, 84.

Clapham, P. A. (1942). J. Helminthology, 20, 31.

Cluver, quoted by Craig, C. F., and Faust, E. C. (1943). "Clinical Parasitology." London, p. 452

Parasitology." J. Helminthology, 22, 73.

Neveu-Lemaire, M. (1936). "Traité d'Helminthologie." Paris, p. 600.

Rogers, J. S. Y., and Tudhope, G. R. (1938). Arch. Dis. Childh., 13, 269. 